\title{
Dinheiro no Brasil: um estudo comparativo do significado do dinheiro entre as regiões geográficas brasileiras
}

\author{
Alice da Silva Moreira \\ Universidade Federal do Pará
}

\begin{abstract}
Resumo
Este estudo comparou o significado do dinheiro predominante nas regiões brasileiras usando a Escala de Significado do Dinheiro (ESD), composta pelos componentes Desigualdade, Progresso, Cultura, Poder, Desapego, Conflito, Estabilidade, Sofrimento e Prazer. O estudo foi conduzido com amostra de 760 sujeitos, $60 \%$ mulheres, com idades, ocupações e renda variadas, e mais de cinco anos de residência no local. Os resultados indicaram diferenças significativas em todos os componentes, exceto Prazer e Sofrimento, e padrões diferenciados: maior Estabilidade no Norte, maior Conflito e Desapego no Nordeste, menor Estabilidade e Poder no Distrito Federal, menor Conflito e Poder no Sul, e no Sudeste, maior Poder, Desigualdade, Cultura, Prazer e Sofrimento e menor Desapego. Exame separado da região Sudeste indicou maior diversidade interna do que entre as regiões do país. Estes resultados são discutidos a partir de diferenças históricoculturais e estereótipos, indicando a sensibilidade da ESD para discriminar perfis de significado do dinheiro.

Palavras-chave: Significado do dinheiro, Psicologia Econômica, Psicologia do Dinheiro, Diferenças regionais, Diferenças sócioculturais.
\end{abstract}

\begin{abstract}
Money in Brazil: A comparative study about the meaning of money among Brazilian geographic regions. This study compared the meaning of money that prevail in Brazilian Regions using the Money Meaning Scale (MMS), composed by Inequality, Culture, Power, Progress, Detachment, Conflict, Stability, Pain and Pleasure Factors. The study was carried out with a sample of 760 subjects, $60 \%$ women, with varied ages, occupation and income, and more than five years living in the place. Results indicated significant differences in all components, except Pleasure and Pain, and differential patterns: higher Stability in the North, higher Conflict and Detachment in the Northeast, lower Stability and Power in the Federal District, lower Power and Conflict in the South, and in the Southeast higher Power, Inequality, Culture, Pleasure and Pain, and lower Detachment. A separated exam of the Southeast showed a higher internal diversity than among Brazilian Regions. These results are discussed considering historic-cultural aspects and stereotypy. It indicated that MMS is sensitive to discriminate meaning of money profiles.
\end{abstract}

Key words: Meaning of money, Economic Psychology, Psychology of Money, Regional differences.

A conversibilidade entre moedas faz do dinheiro um objeto concomitantemente universal (etic) e específico a culturas nacionais (emic); portanto, um objeto privilegiado para estudos comparativos transculturais. A compreensão das semelhanças e diferenças no significado do dinheiro entre países pode trazer contribuições relevantes não apenas para a ciência, mas também para a política e o comércio internacionais. Mas embora a utilização de culturas nacionais como unidades de análise seja defendida, também é ressaltado o risco de perder a diversidade interna, que se torna mais grave em países onde convivem um número subculturas (Smith \& Bond, 1998). Há também que considerar que a especificidade do significado do dinheiro não se limita ao nível da nacionalidade, mas continua realizando-se progressivamente nos níveis de grupos e indivíduos. Por seu tamanho e especificidades geográficas, históricas, econômicas e culturais de suas regiões, o Brasil pode ser considerado um exemplo de país demandando estudos comparativos internos. Este trabalho explora perfis regionais de significado atribuído ao dinheiro, detectando influências sócio-econômico-culturais sobre este significado e contribuindo para o conhecimento sócio-psicológico da realidade brasileira.

\section{Significado do dinheiro}

Considerando-se que o dinheiro participa de todos os momentos da vida econômica cotidiana e que esta constitui parte significativa da vida social, o estudo das atitudes frente ao dinheiro e variáveis relacionadas deve ser um tópico relevante para a psicologia. Compreender como os fenômenos econômicos afetam a vida dos indivíduos e, por sua vez, como 
o comportamento destes pode influenciar a economia é um dos objetivos da disciplina Psicologia Econômica. A pesquisa sobre o significado do dinheiro tem avançado nos últimos anos, buscando delimitar a estrutura cognitiva deste construto e variáveis a ele relacionadas. No âmbito internacional, os quatro instrumentos mais conhecidos indicaram uma estrutura multifatorial, variando entre quatro e seis fatores ou componentes:

1. The Modified Semantic Differential ou Diferencial Semântico Modificado (Wernimont \& Fitzpatrick, 1972). Esta escala foi constituída pelos componentes Fracasso-Vergonha, Aceitabilidade Social, Atitude "ora-ora" (ou desimportância), Pecado Moral e Segurança Confortável. Através dela, foram percebidas diferenças entre pessoas empregadas e desempregadas e entre os sexos.

2. The Money Attitude Scale ou Escala de Atitudes para Dinheiro (Yamauchi \& Templer, 1982). Os componentes desta escala - Poder-prestígio, Retenção, Desconfiança, Qualidade nas Compras e Ansiedade - correlacionaram-se principalmente a variáveis psicológicas, como maquiavelismo, obsessão, paranóia e ansiedade. Também foram apontadas diferenças de sexo (Gresham \& Fontenote, 1989; Yamauchi \& Templer, 1982) e nacionalidade (Medina, Saegert, \& Gresham, 1996).

3. Money Beliefs and Behaviour Scale ou Escala de Crenças e Comportamentos Monetários (Furnham, 1984). Foram encontradas correlações significativas dos componentes Obsessão, Poder/gastar, Retenção, Segurança-conservativa, Inadequação e Esforço-habilidade com as variáveis sexo, nível educacional, renda, posição política, alienação, Ética Protestante do Trabalho (EPT) e conservadorismo social.

4. The Money Ethic Scale ou Escala Ética do Dinheiro (Tang, 1992). Na primeira versão desta escala, os componentes Bom, Mal, Realização, Respeito, Orçamento e Poder-liberdade relacionaram-se a variáveis como: renda, idade, sexo, valores, satisfação com a vida, trabalho, pagamento, promoções, supervisores e colegas, além de variáveis psicológicas do tipo: locus de controle, irritação e ansiedade. Após alguns estudos empregando variações desta escala, Tang (2000) concluiu que pessoas com altos escores em uma medida geral da mesma acreditam que o dinheiro é bom, representa sucesso e que são capazes de controlar seus orçamentos. Também tendem a ser mais velhas e ter fortes valores econômicos, fracos valores religiosos, comportamento controlador, pouca satisfação no trabalho e muita habilidade política (Tang, 2000).

Diferenças entre países nas atitudes frente ao dinheiro têm sido menos focalizadas como objeto de estudo, mas aparecem como variáveis independentes em pesquisas endereçando o desenvolvimento econômico. Furnham, Kirkcaldy e Lynn (1994) estudaram as atitudes nacionais frente a competitividade, dinheiro e trabalho como variáveis explicativas, entre outras, para as diferenças entre primeiro, segundo e terceiro mundos em amostra de 41 países. Atitudes (positivas) frente ao dinheiro e à poupança foram compostas por itens selecionados das escalas de Yamauchi e Templer (1982) e de Furnham (1984). Os resultados indicaram correlação positiva entre atitudes frente ao dinheiro e Produto Interno Bruto $(0,55)$, com padrões diferenciados para a Europa, as três Américas e os países asiáticos. Lynn, Yamauchi e
Tachibana (1991) indicaram escores mais altos para estudantes japoneses que para estudantes ingleses em competitividade e valorização do dinheiro. Outro estudo (Furnham, 1996) indicou que dinheiro foi considerado mais importante nos países mais pobres enquanto nos países mais ricos haveria menor preocupação em ganhar e poupar dinheiro.

\section{Significado do dinheiro no Brasil}

A Escala de Significado do Dinheiro (ESD) foi desenvolvida no Brasil por Moreira e Tamayo (1999a), através de procedimento que incluiu extenso levantamento de dados preliminares sobre a perspectiva do senso comum, organização destes dados através de categorização por grupos de juízes independentes e análise teórica baseada em esquema referencial compreensivo das ciências sociais. Sua validação contou com numerosa amostra de sujeitos de todas as regiões geográficas com características demográficas variadas. Os resultados da Análise dos Componentes Principais com rotação Varimax indicaram uma estrutura de nove componentes, com os seguintes alpha de Cronbach: Poder $(0,88)$, Conflito $(0,87)$, Prazer $(0,84)$, Progresso $(0,80)$, Cultura $(0,76)$, Desapego $(0,73)$, Sofrimento $(0,67)$, Desigualdade $(0,66)$ e Estabilidade $(0,57)$ (Para maiores detalhes ver Moreira, 2000; Moreira \& Tamayo, 1999a). As definições dos componentes ficaram como segue:

Poder: "Afirmação da crença de que o dinheiro é fonte de autoridade, prestígio e reconhecimento social, assegurando uma situação privilegiada a quem o possui e permitindo burlar normas sociais".

Conflito: "Significado negativo atribuído ao dinheiro no contexto das relações interpessoais cotidianas. Afirmação da crença de que o dinheiro provoca desconfiança, conflitos, desavenças, mortes, falsidade, neurose e oportunismo".

Prazer: "Afirmação de crenças e sentimentos positivos relacionados ao dinheiro. Conseqüências positivas atribuídas ao dinheiro, tais como: prazer, felicidade, bem-estar psicológico, auto-estima, esperança e harmonia nas relações interpessoais".

Progresso: "Significado positivo atribuído ao dinheiro em relação ao contexto social mais amplo, como promotor de progresso para as sociedades e a humanidade. Afirmação da crença de que o dinheiro é capaz de resolver problemas sociais e construir um mundo melhor".

Cultura: "Significado positivo atribuído ao dinheiro como promotor do desenvolvimento cultural em geral. Disposição pessoal de investir dinheiro no desenvolvimento das ciências, artes, cultura e tecnologia".

Desapego: "Afirmação de crenças e comportamentos envolvendo uma oposição entre dinheiro e espiritualidade e a necessidade de dar mais importância aos valores de solidariedade e generosidade que aos bens materiais".

Sofrimento: "Significado negativo atribuído ao dinheiro no nível da subjetividade envolvendo fortes emoções carregadas de sofrimento e aspectos de desequilíbrio emocional, tais como: angústia, depressão, frustração e impotência".

Desigualdade: "Significado negativo atribuído ao dinheiro como fonte de desigualdade social, segregação e precon- 
ceito. Afirmação da crença de que o dinheiro cria uma forte demarcação no espaço social, dificultando o acesso de quem não o possui a lugares e pessoas".

Estabilidade: "Significado positivo atribuído ao dinheiro como fonte de estabilidade e segurança. Afirmação de crenças e comportamentos envolvendo a importância de ter as necessidades básicas asseguradas e estabilidade financeira".

Utilizando Análise de Regressão Múltipla, Moreira (2000) indicou significativo poder de predição de variáveis econômicas (renda e número de dependentes), demográficas (sexo, idade, escolaridade, tipo de ocupação) e das regiões geográficas sobre os componentes da ESD, com peso significativo das regiões para todos os componentes. Exame em separado da amostra da região Sudeste indicou influência significativa do estado de residência e da variável residir em capitais versus cidades do interior sobre os componentes, exceto Sofrimento, que não apresentou resultados significativos para nenhuma das variáveis examinadas (Moreira, 2000; Moreira \& Tamayo, 1999b).

A influência das prioridades individuais de valores sobre o significado que indivíduos de diferentes contextos culturais atribuem ao dinheiro foi explorada por Moreira (2000), partindo de hipóteses fundamentadas pela Teoria dos Valores (Schwartz, 1994; 1999). O estudo comparou três amostras de estudantes de Psicologia provenientes de dois países: Inglaterra e Brasil (cidades de Belém e Brasília), usando uma versão bicultural da ESD desenvolvida e validada para este fim, composta por seis componentes (Prazer, Poder, Conflito, Desapego, Progresso e Cultura). Os resultados da comparação, depois de controlados os efeitos de sexo, idade e renda, indicaram médias mais altas para os belenenses em todos os componentes, sugerindo percepção mais complexa ou contraditória do dinheiro, enquanto os brasilienses ficaram no meio termo entre ingleses e belenenses. Estes resultados estão em acordo com as diferenças esperadas a partir da caracterização do nível cultural da Teoria dos Valores e confirmam as conclusões de Furnham e outros (1996) de que maior pobreza contextual leva a maior importância atribuída ao dinheiro.

\section{Caracterização das regiões brasileiras}

O Brasil possui um território de $8.511 .965 \mathrm{~km}^{2}$, onde vivem mais de 160 milhões de pessoas. A região Norte equivale a aproximadamente metade deste território e tem recebido apelidos como "pulmão do planeta", "inferno verde" ou "paraíso esquecido" (Brazilian Embassy in London, 1998). Para alguns de seus habitantes, a bacia amazônica é comparável a um imenso útero: quente, úmido, generoso e protetor. Protegido também. Os portugueses chegaram a esta área dois séculos depois do descobrimento e a região permaneceu praticamente inexplorada até o século XIX. Durante o efêmero ciclo da borracha, entre 1885 e 1910, a população aumentou seis vezes e a renda média doze vezes. Foi um período de intensa atividade econômica e cultural, do qual muitas cidades ainda conservam alguns majestosos edifícios (Instituto Brasileiro de Turismo [EMBRATUR], 1998). Talvez daí veio a expressão popular que caracteriza o estado do Pará como “terra do já teve". A partir da década de 70, a região tornou-se alvo da atenção internacional por causa dos problemas de desmatamento e, mais recentemente, tem sido re-enfatizado seu potencial para o turismo ecológico (Brazilian Embassy in London, 1998).

O Nordeste é caracterizado como "o berço da civilização portuguesa no país" (EMBRATUR, 1998); onde foi rezada a primeira missa, abatido o primeiro índio e chicoteado o primeiro escravo, como nos lembra a música de Gilberto Gil. Tem dado ao país alguns de seus mais respeitáveis nomes nas letras, artes, ciências e religião. Do ponto de vista governamental, as possibilidades econômicas e turísticas da região são sempre enfatizadas. Do ponto de vista do estereótipo dominante, são freqüentemente enfatizados os problemas crônicos e insolúveis da seca, a contínua migração para o Sudeste e a inabalável fé do povo nordestino.

O Distrito Federal é um pequeno recorte de $5.814 \mathrm{~km}^{2}$ de terra, incrustado em um platô 1.100 metros acima do nível do mar, bem no centro do país, eqüidistante de seus pontos extremos Norte e Sul. A capital do país, Brasília, foi fundada em 21 de abril de 1960, produto do sonho visionário do presidente Juscelino Kubitscheck, esboçada pela arquitetura futurista de Oscar Niemayer e materializada pelos braços dos "candangos" (primeiros imigrantes). Foi progressivamente povoada por gente vinda de todos os cantos do Brasil, além de ser a sede das embaixadas. A cada quatro anos, um novo contingente de políticos recém-eleitos com suas famílias e numerosas equipes de assessores convergem para o planalto central, gerando uma população flutuante de alto poder aquisitivo.

A região Sudeste concentra a maior densidade populacional e de atividade industrial do Brasil. É também uma região rica em minerais e sua agricultura é a mais avançada do país, exportando tanto grãos como produtos industrializados (Brazilian Embassy in London, 1998). A marca da região são as disparidades econômicas, que caracterizam principalmente as megalópoles São Paulo e Rio de Janeiro: conjunções desordenadas de favelas e arranha-céus, convivência cada vez menos pacífica entre miséria e ostentação. A diversidade cultural interna da região pode ser traduzida em termos dos estereótipos que contrastam o "workaholic paulistano", o "malandro carioca" e o "come-quieto mineiro".

A região Sul é considerada economicamente quase tão desenvolvida quanto o Sudeste, com bom equilíbrio entre produção rural e industrial (Brazilian Embassy in London, 1998). É a região apontada como a mais diferenciada do resto do país, o que às vezes é usado como justificativa para discursos e movimentos separatistas. Além do clima temperado, a imigração alemã, italiana e polonesa é responsabilizada pela marcante influência européia, conservada nos corpos, na arquitetura, no folclore, alimentação e sotaques da região. "Crianças louras, olhos azuis e forte sotaque. Estamos realmente no Brasil?"' (EMBRATUR, 1998).

\section{Método}

\section{Amostra}

A amostra foi constituída por 760 sujeitos, $60 \%$ do sexo feminino, idades variando entre 14 e 58 anos, renda familiar 
mensal entre 120 e 8.000 reais mensais, escolaridade a partir do segundo grau incompleto e ocupações variadas. Todos residiam há mais de cinco anos no Distrito Federal e em cidades das outras quatro regiões geográficas brasileiras, na seguinte proporção: Distrito Federal $(\mathrm{DF})=25,8 \%$; Norte $(\mathrm{N})=$ $19,2 \% ;$ Nordeste $(\mathrm{NE})=10,1 \% ;$ Sudeste $(\mathrm{SE})=29,5 \% ;$ Sul $(\mathrm{S})$ $=15,4 \%$.

\section{Procedimento}

Questionários auto-aplicáveis foram enviados a colaboradores voluntários em diversos pontos do país, através de correio. Eles incluíam 158 itens sobre o significado do dinheiro, com escalas Likert de 1 (discordo fortemente) a 5 (concordo fortemente), e um questionário de dados pessoais. Os colaboradores solicitavam a participação dos sujeitos, entregavam os questionários, recebiam-nos e enviavam-nos de volta pelo correio. A situação em que os respondentes eram contatados e o prazo de devolução variou em cada lugar, em função de especificidades locais. A coleta ocorreu nos anos de 1997 a 1998.

\section{Resultados}

Os 82 itens que alcançaram cargas fatoriais maiores que 0,40 na validação da ESD (ver Moreira, 2000) foram usados para as análises deste estudo. Os alpha de Cronbach para cada um dos nove componentes foram os seguintes: Poder = 0,87; Conflito $=0,85 ;$ Prazer $=0,84 ;$ Cultura $=0,77$; Progresso $=0,76 ;$ Desapego $=0,70 ;$ Sofrimento $=0,65 ;$ Desigualdade $=$ 0,64 e Estabilidade $=0,51$. Os escores foram apurados através da média dos itens para cada sujeito. As médias em cada componente para a amostra de brasileiros como um todo e para as regiões estão em ordem decrescente na Tabela 1 .
Estabilidade foi o componente unanimemente predominante, acontecendo o mesmo em relação ao que ficou em último lugar: Sofrimento. O segundo componente para a amostra geral de brasileiros foi Desigualdade, ocorrendo o mesmo no DF e no Sudeste. No Nordeste e no Sul, este componente caiu para o terceiro e no Norte para quarto lugar. Progresso foi o terceiro na ordem geral e no DF, subindo para segundo nas regiões Norte, Nordeste e Sul. Progresso e Cultura empataram em terceiro no Sudeste. O quarto componente foi Cultura, no Brasil, no DF e no Sul, subindo para terceiro no Norte e no Sudeste, mas caindo para quinto no Nordeste, superado por Desapego. O quinto componente para brasileiros em geral foi Conflito, que subiu para quarto lugar no Sudeste, caindo para sexto nas demais regiões. Desapego ocupou o sexto lugar no geral e no Sudeste, subindo para quinto no DF, Norte e Sul e para o quarto no Nordeste, que teve a média mais alta neste componente. Poder foi o sétimo no Brasil, DF, Norte e Nordeste, subindo para quinto no Sudeste e caindo para oitavo no Sul, superado por Prazer. Exceto para os sulistas, Prazer ocupou o penúltimo lugar em todas as regiões.

Em resumo, a análise das ordenações de médias indicou que as amostras do DF e do Sudeste apresentaram poucas diferenças em relação ao Brasil, envolvendo apenas um par de componentes por vez: Desapego superou Conflito no DF e Poder superou Desapego no Sudeste. No Sul, ocorreram três inversões, também envolvendo um par de componentes cada: Progresso superou Desigualdade; Desapego superou Conflito; Prazer superou Poder. No Norte e Nordeste, as alterações foram mais freqüentes e acentuadas, envolvendo mais de dois componentes por inversão, como a queda de Desigualdade do segundo para o quarto lugar no Norte e a subida de Desapego do sexto para quarto lugar no Nordeste.

Tabela 1

Médias em cada componente para a amostra geral do Brasil e separadamente para cada região.

\begin{tabular}{cccccc}
\hline BRASIL & DF & $\mathrm{N}$ & NE & SE & S \\
\hline Estabilidade & Estabilidade & Estabilidade & Estabilidade & Estabilidade & Estabilidade \\
4,26 & 4,13 & 4,41 & 4,30 & 4,30 & 4,17 \\
Desigualdade & Desigualdade & Progresso & Progresso & Desigualdade & Progresso \\
3,95 & 3,91 & 3,99 & 4,00 & 4,06 & 3,98 \\
Progresso & Progresso & Cultura & Desigualdade & Progresso & Desigualdade \\
3,91 & 3,77 & 3,93 & 3,98 & 3,92 & 3,94 \\
Cultura & Cultura & Desigualdade & Desapego & Cultura & Cultura \\
3,82 & 3,73 & 3,84 & 3,89 & 3,92 & 3,69 \\
Conflito & Desapego & Desapego & Cultura & Conflito & Desapego \\
3,65 & 3,67 & 3,75 & 3,78 & 3,68 & 3,46 \\
Desapego & Conflito & Conflito & Conflito & Poder & Conflito \\
3,63 & 3,66 & 3,70 & 3,76 & 3,60 & 3,45 \\
Poder & Poder & Poder & Poder & Desapego & Prazer \\
3,44 & 3,35 & 3,43 & 3,47 & 3,53 & 3,38 \\
Prazer & Prazer & Prazer & Prazer & Prazer & Poder \\
3,33 & 3,26 & 3,32 & 3,21 & 3,41 & 3,25 \\
Sofrimento & Sofrimento & Sofrimento & Sofrimento & Sofrimento & Sofrimento \\
2,48 & 2,51 & 2,47 & 2,45 & 2,55 & 2,33 \\
\hline
\end{tabular}



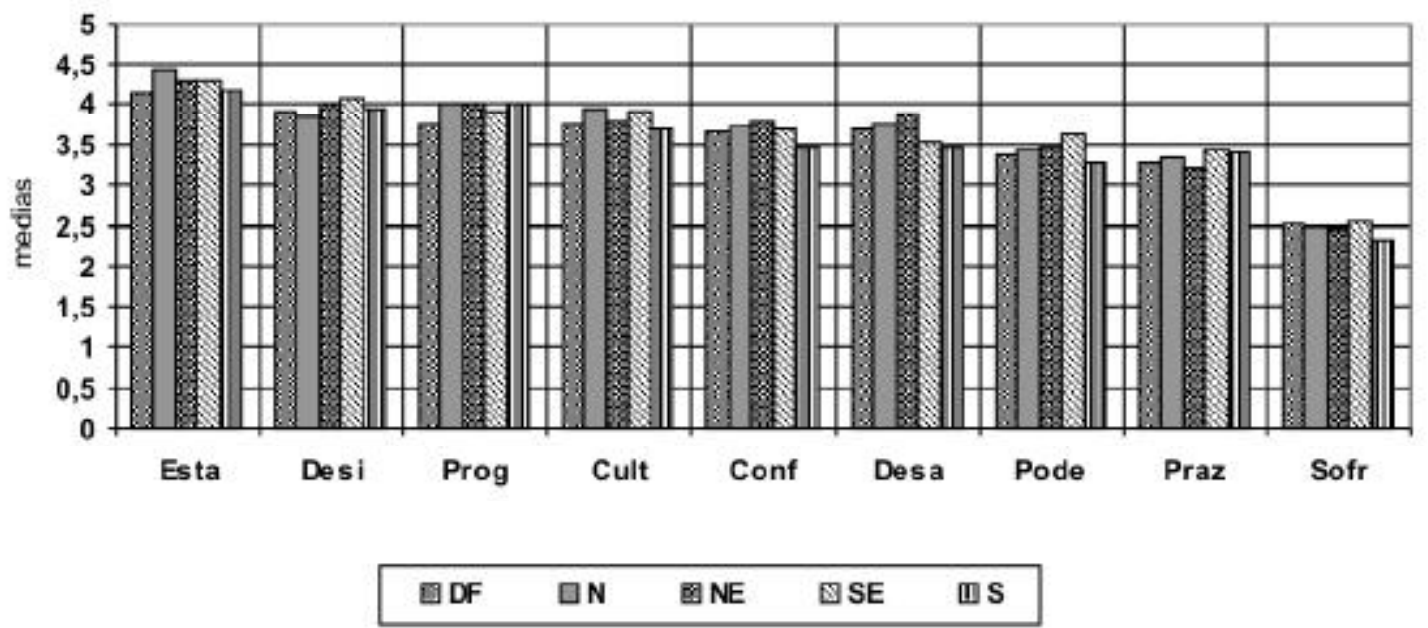

Figura 1

Médias dos componentes por região na amostra do Brasil.

A comparação entre as médias das regiões foi feita através de Análise de Variância Multivariada (MANOVA), após a verificação de que os dados agrupados davam suporte aos pressupostos para a análise multivariada (Tabachnick \& Fidell, 1996). Os resultados dos testes Wilks' Lambda e Pillai's Trace apontaram efeito significativo da variável região geográfica sobre a combinação linear dos nove componentes ( $p$ $<0,001)$. Os níveis de significância dos testes de efeitos principais para cada componente e testes post hoc estão na Tabela 2 e a configuração das médias pode ser vista na Figura 1.

$O$ teste de efeitos principais indicou diferenças significativas para região geográfica em sete componentes, excetuando apenas Prazer e Sofrimento. Mas para Progresso e Cultura, as comparações post hoc não indicaram significância estatística entre pares de amostras. As diferenças mais fortes foram para Estabilidade, Desapego e Poder. As comparações post hoc para Estabilidade indicaram que a média do Norte destacou-se em relação ao Sul e DF, enquanto o Sudeste foi superior ao DF. Em Desapego, Norte e Nordeste tiveram médias mais altas que Sul e Sudeste, destacando-se principalmente a diferença entre Nordeste e Sul. Em relação a Poder, o Sudeste teve médias maiores que o Sul e o DF. Os resultados no componente Conflito confirmaram o que o gráfico sugere: médias mais baixas para os sulistas em relação ao resto do país, exceto o DF. Para Desigualdade, apenas a média do Norte foi menor que a do Sudeste.

Em outras palavras, os resultados do DF apresentaramse geralmente como uma espécie de meio termo entre as regiões, destacando-se uma percepção mais fraca do dinheiro como fonte de Estabilidade e Poder. No Sul, percebeu-se uma visão menos negativa do dinheiro, com médias mais baixas em Conflito, Desapego e Poder, embora também baixa em Estabilidade. $O$ perfil nortista indicou um sentido mais forte de Estabilidade e Desapego, com menor percepção de Desigualdade, sugerindo uma percepção mais tradicionalista. $\mathrm{O}$ perfil nordestino apresentou uma visão negativa permeada com espiritualidade, ou seja: Desapego e Conflito. No Sudeste, destacaram-se Poder, Conflito e Desigualdade como mais fortes e Desapego como mais fraco: uma imagem negativa relacionada a auto-interesse.

\section{Exame separado da região sudeste}

A região Sudeste tinha maior número de sujeitos na amostra e heterogeneidade interna, ou seja: pessoas residindo em três estados, em capitais e cidades do interior. Por isso, pareceu viável e interessante explorá-la separadamente. Depois de eliminados os respondentes das outras regiões, a amostra ficou constituída por 217 sujeitos, 65,4\% do sexo feminino,

Tabela 2

Resultados da MANOVA para a variável região geográfica.

\begin{tabular}{|c|c|}
\hline EFEITO GERAL & TESTE POST HOC \\
\hline Estabilidade ${ }^{(* * *)}$ & $\begin{array}{l}\mathrm{N}>\mathrm{DF}^{(* * *)} \\
\mathrm{N}>\mathrm{S}^{(* *)} \\
\mathrm{SE}>\mathrm{DF}^{(*)}\end{array}$ \\
\hline Desigualdade $\left(^{(*)}\right.$ & $\mathrm{SE}>\mathrm{N}^{(*)}$ \\
\hline Progresso ${ }^{(*)}$ & \\
\hline Cultura ${ }^{(*)}$ & \\
\hline Conflito (") & $\begin{array}{l}\mathrm{N}>\mathrm{S}^{(*)} \\
\mathrm{NE}>\mathrm{S}^{(*)} \\
\mathrm{SE}>\mathrm{S}^{(*)}\end{array}$ \\
\hline Desapego ${ }^{(*)}$ & $\begin{array}{l}\mathrm{NE}>\mathrm{S}^{(+\infty)} \\
\mathrm{NE}>\mathrm{SE}^{(* *)} \\
\mathrm{N}>\mathrm{S}^{(*+)} \\
\mathrm{N}>\mathrm{SE}^{(*)}\end{array}$ \\
\hline Poder ${ }^{(\cdots *)}$ & $\begin{array}{l}\mathrm{SE}>\mathrm{S}^{(* *)} \\
\mathrm{SE}>\mathrm{DF}^{(*)}\end{array}$ \\
\hline
\end{tabular}


$56,2 \%$ de residentes no estado de São Paulo (SP), 30\% no estado do Rio de Janeiro (RJ) e 13,8\% no estado de Minas Gerais (MG). Do total de respondentes, 29,5\% morava em capitais e 70,5\% em cidades do interior. Os alpha de Cronbach para os componentes foram os seguintes: Poder $=0,87$; Prazer $=0,84 ;$ Conflito $=0,83$; Progresso $=0,79 ;$ Cultura $=0,79$; Desapego $=0,70 ;$ Desigualdade $=0,62 ;$ Sofrimento $=0,53 \mathrm{e}$ Estabilidade $=0,42$. Foram repetidos os mesmos procedimentos, de modo a permitir a comparação com a análise anterior.

Comparando internamente quanto à ordenação das médias, vemos que as inversões de ordem nas áreas de residência em relação à região como um todo foram mais frequientes e envolveram sempre mais que um par de componentes por vez (Tabela 3).

O primeiro componente, Estabilidade, manteve o mesmo lugar no geral e em todas as áreas, bem como o último colocado, Sofrimento, confirmando o consenso nacional a este respeito. Desigualdade manteve o segundo lugar em todas as áreas, menos o interior-SP, onde caiu para terceiro. Mas as variações de ordem para os outros seis componentes foram mais acentuadas. Progresso variou entre o terceiro lugar (capital-RJ) e o quinto (capital-SP, interior-RJ e interior-MG). Cultura variou entre o segundo (interior-SP) e o sétimo lugares (capital-RJ). Conflito variou entre o terceiro (interior-RJ) e o sétimo (interior-São Paulo). Poder ocupou desde o quinto lugar (interior-SP) até o oitavo (capital-SP). Desapego foi de quarto (interior-MG) a oitavo (interior-SP) e Prazer variou entre o quinto (interior$\mathrm{SP}$ ) e o oitavo lugares (capital-RJ, interior-RJ e interior-MG).

Como na análise para as regiões, aqui também os resultados do teste multivariado da MANOVA apontaram efeito significativo da área de residência sobre a combinação linear dos componentes $(\mathrm{p}<0,001)$. Os testes de efeitos principais foram altamente significativos para todos os componentes, com níveis mais fracos apenas para Desigualdade e Sofrimento, o que confirmou a suposição de diversidade que levou a explorar separadamente a região.

As comparações post hoc para Estabilidade indicaram que a média do interior-SP foi maior que a da capital-SP e do interior-MG. Para Desigualdade, o interior-SP e o interior-RJ tiveram médias maiores que o interior-MG. Progresso teve média significativamente maior no interior que na capital de São Paulo e no interior-MG. Em Cultura, o interior paulista teve média maior que a capital-RJ e que o interior mineiro. Em Conflito, o interior-RJ teve média maior que a capital-SP, o interior-SP e o interior-MG. De modo geral, as capitais tiveram médias mais baixas em Poder que os interiores. Quanto a Desapego, tanto a capital como o interior do Rio de Janeiro tiveram médias maiores que a capital e o interior de São Paulo. Em Prazer, o interior paulista superou todas as áreas, exceto a capital daquele estado. Em Sofrimento, apenas a diferença entre capital e interior de São Paulo foi significativa.

Resumindo, os resultados indicaram maior diversidade interna na região Sudeste que no Brasil como um todo, não apenas em relação às ordenações das médias como aos "perfis" que puderam ser percebidos. $\mathrm{O}$ destaque foi para o interior do estado de São Paulo, onde o dinheiro apareceu de maneira mais forte como fonte de Estabilidade, Desigualdade, Progresso, Cultura, Poder, Prazer e Sofrimento, com médias mais baixas que outras áreas da região em Conflito e Desapego. Neste estado, a capital e o interior diferenciaram-se marcadamente entre si. $\mathrm{O}$ interior apresentou médias superiores às da capital em todos os componentes, sendo as diferenças mais acentuadas para Progresso e Poder. Já no estado do Rio de Janeiro, foi indicada uma percepção mais acentuada

Tabela 3

Médias em cada componente no Sudeste em gersal e para cada área de residência

\begin{tabular}{cccccc|}
\hline SE & SP-capital & SP-interior & RJ-capital & RJ-interior & MG-interior \\
\hline Estabilidade & Estabilidade & Estabilidade & Estabilidade & Estabilidade & Estabilidade \\
4,30 & 4,15 & 4,50 & 4,24 & 4,31 & 4,04 \\
Desigualdade & Desigualdade & Cultura & Desigualdade & Desigualdade & Desigualdade \\
4,06 & 3,95 & 4,22 & 4,10 & 4,21 & 3,78 \\
Progresso & Cultura & Desigualdade & Progresso & Conflito & Cultura \\
3,92 & 3,87 & 4,20 & 4,06 & 4,04 & 3,74 \\
Cultura & Conflito & Progresso & Conflito & Cultura & Desapego \\
3,92 & 3,59 & 4,15 & 3,77 & 3,97 & 3,61 \\
Conflito & Progresso & Poder & Desapego & Progresso & Progresso \\
3,68 & 3,57 & 3,94 & 3,76 & 3,93 & 3,60 \\
Poder & Poder & Prazer & Poder & Desapego & Conflito \\
3,60 & 3,30 & 3,69 & 3,38 & 3,83 & 3,47 \\
Desapego & Prazer & Conflito & Cultura & Poder & Poder \\
3,53 & 3,35 & 3,63 & 3,33 & 3,59 & 3,36 \\
Prazer & Desapego & Desapego & Prazer & Prazer & Prazer \\
3,41 & 3,33 & 3,37 & 3,04 & 3,21 & 3,26 \\
Sofrimento & Sofrimento & Sofrimento & Sofrimento & Sofrimento & Sofrimento \\
2,55 & 2,33 & 2,72 & 2,32 & 2,66 & 2,41 \\
\hline
\end{tabular}


Tabela 4

Resultados da MANOVA para a variável área de residência

\begin{tabular}{|c|c|}
\hline EFEITO GERAL & TESTE $P O S T H O C$ \\
\hline Estabilidade $^{(* \cdots)}$ & $\begin{array}{l}\text { interior-SP }>\text { capital-SP } \\
\text { interior-SP }>\text { interior- } \\
\mathrm{MG}^{(* *)}\end{array}$ \\
\hline Desigualdade ${ }^{(* *)}$ & $\begin{array}{l}\text { interior-SP }>\text { interior- } \mathrm{MG}^{(*)} \\
\text { interior-RJ }>\text { interior- } \mathrm{MG}^{(*)}\end{array}$ \\
\hline Progresso ${ }^{(* *+)}$ & $\begin{array}{l}\text { interior-SP }>\text { capital-SP } \\
\text { interior-SP }>\text { interior- } \mathrm{MG}^{(*)}\end{array}$ \\
\hline Cultura ${ }^{(\operatorname{sax})}$ & $\begin{array}{l}\text { interior-SP }>\text { capital- } \mathrm{RJ}^{(* *)} \\
\text { interior-SP }>\text { interior-MG } \mathrm{MG}^{(*)}\end{array}$ \\
\hline Conflito ${ }^{(* * *)}$ & $\begin{array}{l}\text { interior-RJ }>\text { capital-SP } \\
\text { interior-RJ }>\text { interior- } \\
\mathrm{MG}^{(* *)}\end{array}$ \\
\hline Poder ${ }^{(\infty+\infty)}$ & $\begin{array}{l}\text { interior-SP }>\text { capital- } \\
\mathrm{SP}^{(* * *)} \\
\text { interior-SP }>\text { interior- } \\
\mathrm{MG}^{(* * *)} \\
\text { interior-SP }>\text { capital-RJ } J^{(* *)}\end{array}$ \\
\hline Desapego ${ }^{(* * *)}$ & 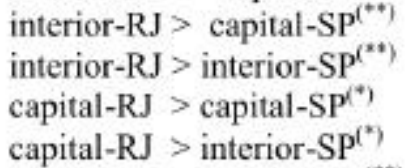 \\
\hline Prazer ${ }^{(* * *)}$ & $\begin{array}{l}\text { interior-SP }>\text { capital-RJ } J^{(* *)} \\
\text { interior-SP }>\text { interior- } \mathrm{KJ}^{(* *)} \\
\text { interior-SP }>\text { interior- } \\
\mathrm{MG}^{(*)}\end{array}$ \\
\hline Sofrimento ${ }^{(*)}$ & interior-SP $>$ capital-SP( ${ }^{(*)}$ \\
\hline
\end{tabular}

de Conflito e Desapego, com percepção menor de Prazer e Cultura que outras áreas do Sudeste brasileiro. Olhando separadamente capital e interior, neste estado, ressalta-se que a capital teve média mais alta que o interior apenas em Progresso, com menor percepção de Cultura e Prazer que o interior, mas também baixa em Sofrimento. $\mathrm{O}$ interior de Minas teve médias mais baixas que todas as outras áreas em Desigualdade e Conflito, o que indica uma visão menos negativa do dinheiro. Na maior parte dos componentes, os mineiros ficaram como uma espécie de meio termo entre as áreas. Assemelharam-se mais a moradores das capitais nas baixas médias para Estabilidade, Poder e Sofrimento, mas ficaram mais próximos às médias altas dos outros interiores em Cultura. Assemelharam-se mais ao Rio na baixa percepção de Prazer, da capital de São Paulo na baixa percepção de Progresso, e ficaram no meio do caminho entre Rio e São Paulo quanto a Desapego.

\section{Discussão}

Este estudo comparativo do significado do dinheiro no Brasil apresenta limites de generalização dos resultados relativamente estreitos, levando em conta as limitações na amplitude das variáveis renda, idade e escolaridade, que não refletem a realidade nacional. Além disso, por dependermos da disponibilidade dos colaboradores voluntários, não foi possível controlar alguns vieses de distribuição entre as regiões, por exemplo, das variáveis ocupação, idade e níveis de renda. Mesmo considerando essas limitações, os resultados encontrados nas descrições de perfis são úteis para compreender melhor o funcionamento da ESD, e compatíveis com informações coletadas através de dados histórico-geográficos, informações turísticas, estereótipos sociais e observações pessoais.

$\mathrm{O}$ estereótipo do brasileiro que habita o "Pulmão do Mundo" ou a "Terra do Já Teve" parece coerente com os resultados, que foram obtidos com amostra proveniente majoritariamente dos estados do Pará e Roraima. A percepção mais forte de Estabilidade parece condizente com o ritmo lento de crescimento econômico. A média mais baixa em Desigualdade sugere que, do ponto de vista leigo, as diferenças econômicas existentes podem estar sendo minimizadas ou justificadas pelo preconceito sobre o "caboclo indolente e sensual", mimado por uma natureza pródiga em peixes e frutos. A média em Cultura, quase tão alta como a do Sudeste, também parece condizente com a marca histórica do ciclo da borracha. Como no interior de São Paulo, talvez as pessoas fiquem mais dispostas a investir naquilo que sentem ter perdido e lhes faz falta. Esta especulação está em acordo com os resultados encontrados em estudo anterior que revelou médias significativamente mais altas em Cultura para Belém e Brasília em comparação com a Inglaterra (Moreira, 2000). Já o estereótipo nordestino, que combina corajoso com resignado e energético com sofredor, encontra correspondência com os resultados de uma imagem negativa do dinheiro, com percepção mais forte de Conflito e Desapego e mais fraca do dinheiro como fonte de Prazer. A maioria dos dados veio do estado da Paraíba, mas também incluiu Ceará, Pernambuco e Bahia. Em comum, as duas regiões menos desenvolvidas do país apresentaram uma diferenciação mais acentuada em relação ao resto do país no que diz respeito à ordem de importância dada aos componentes.

Não surpreende que a capital do país tenha aparecido como um meio termo ou parâmetro central entre as regiões. Isto pode ser interpretado como um indicativo de síntese nacional a partir da convergência de representantes de todas as regiões para esta área. A população flutuante de funcionários de alto escalão, que gerou a média de renda mensal mais alta em nossa amostra, provavelmente também está relacionada à percepção mais fraca de Estabilidade. Interessantemente, o componente Poder também obteve média relativamente baixa, talvez porque a proximidade ao centro político do país faça com que as pessoas percebam o dinheiro mais como consequiência do que como antecedente do poder. Por outro lado, se considerarmos este resultado junto com a média também baixa em Poder na região Sul, é licito imaginar que esta percepção seja conseqüente de menor disparidade econômica interna. Esta hipótese e apoiada pelos resultados de pesquisa anterior, que indicou maior média em Belém em relação a Brasília e em Brasília em relação à Inglaterra (Moreira, 2000).

A análise em separado da região Sudeste permitiu diferenciar internamente as médias dos três estados e explorar o efeito da variável residir em capitais ou interior. A residência 
em área rural ou urbana é uma das variáveis antecedentes relevantes para a Teoria dos Valores, tendo sido apontada uma relação entre residência urbana e Abertura à Mudança e Universalismo (Schwartz, Verkasalo, Antonovsky \& Sagiv, 1997; Smith \& Schwartz, 1997). Evidentemente, não podemos afirmar que as cidades do interior do Brasil caracterizam-se como área rural, e muito menos que os contrastes encontrados neste estudo podem ser generalizados para o país como um todo. Também deveriam ser levadas em conta as diferenças em tamanho das cidades, comparando-se as de pequeno, médio e grande porte. Mesmo assim, as diferenças encontradas revelaram-se sugestivas.

No Rio de Janeiro, os resultados da capital, com as médias mais baixas em Prazer e Cultura, parecem contrastar com o estereótipo hedonista da "cidade maravilhosa", cantado em prosa e verso e vendido a turistas. Parece mais coerente com a imagem de violência e criminalidade recentemente prodigalizada pelos noticiários e o acirramento de problemas urbanos como poluição, congestionamento e queda na qualidade de vida (Brazilian Embassy, 1998). Podemos especular sobre um efeito de contraste entre o estereótipo introjetado e a restrição das possibilidades de aproveitar a vida, levando a duvidar que o dinheiro pode ser fonte de prazer; mas sem chegar a gerar uma imagem oposta, na medida em que a média para Sofrimento também foi baixa. Com relação ao interior do Rio de Janeiro, a maioria dos dados veio de São João de Meriti, cidade de pequeno porte e localização próxima à capital. Neste segmento da amostra foi encontrado um nível mais baixo de renda do que para o restante da região. A relativa semelhança com o Nordeste, pode ser produto de migração, e remete ao próprio nome da cidade: meriti é uma madeira leve, nativa do norte e nordeste do país.

Grosso modo, pode se dizer que o perfil do estado de São Paulo apresentou o maior nível de complexidade. Na "locomotiva" econômica do país, capital e interior mostraram perfis opostos para a maioria dos componentes, provavelmente como efeito do grande contingente de imigrantes vindos de todas as regiões do país e também do exterior em direção à capital paulista. No interior, a maioria dos dados veio de Bauru, cidade de médio porte e baixo nível de atividade industrial, mas com localização próxima à afluente Ribeirão Preto, centro de uma das mais produtivas áreas rurais brasileiras. Segundo depoimentos de moradores, Bauru nasceu a partir do cruzamento de duas linhas de trem, caracterizando-se como uma cidade de trânsito comercial. Viveu período de grande prosperidade no início do século, para experimentar decadência progressiva a partir da desativação da rede ferroviária. A presença das universidades é o fator que mobiliza a vida da cidade, gerando um clima contraditório, misto de acolhimento e resistência aos estudantes que vêm "de fora". Encontramos médias mais altas que no resto da região para sete dos nove componentes, o que pode indicar um modo mais complexo de ver o dinheiro, mais carregado de significados contraditórios. Se olharmos apenas a ordem das médias, vemos que as alterações com relação à da região foram a subida de Cultura do quarto para o segundo lugar, a de Prazer do oitavo para o sexto e a de Poder do sexto para o quarto, o que indica uma visão positiva do dinheiro. As médias em Conflito e Desapego assemelharam-se entre capital e interior, sendo mais baixas que outras áreas, o que confirma uma visão menos negativa. Na capital que "não pode parar", o que mais chamou a atenção foi a média em Progresso, menor que as outras áreas e implicando uma queda do terceiro para o quinto lugar na ordem. Como na capital do Rio de Janeiro, o resultado contrasta com o estereótipo nacional e mereceria pesquisas adicionais, talvez envolvendo também a variável percepção de qualidade de vida.

Em Minas Gerais, foi possível obter dados apenas em Uberlândia, cidade de grande porte e um dos vértices do afluente triângulo mineiro. Em termos geográficos, a cidade está mais próxima de São Paulo do que da capital do estado, mas não temos dados de Belo Horizonte que permitam comparações. Depoimentos de moradores indicam uma grande diversidade cultural interna para o estado de Minas Gerais, a partir de influências determinadas por proximidades geográficas: Poderíamos encontrar o "mineiro-paulista" no triângulo mineiro, o "mineiro-carioca" na região de Juiz de Fora, o "bahianeiro" na divisa com a Bahia, e o "autêntico mineiro", este limitado a Belo Horizonte e Vale do Jequitinhonha. Esta diversidade sugere também a necessidade de outras pesquisas neste estado.

\section{Conclusão}

Este trabalho testou empiricamente a utilidade da Escala de Significado do Dinheiro (ESD) para delinear perfis de significado do dinheiro no contexto brasileiro. Partiu-se da proposição que o dinheiro é um objeto simultaneamente universal e específico a culturas nacionais; e mais ainda, assumindo crescente especificidade em níveis gradativos, como subculturas, grupos até os indivíduos. O perfil nacional, agrupando pessoas de todas as áreas geográficas, colocou em ordem decrescente de importância os componentes Estabilidade, Desigualdade, Progresso, Cultura, Conflito, Desapego, Poder, Prazer e Sofrimento, com unanimidade sobre os dois componentes extremos. Interessante notar que entre o segundo e o quarto lugares, ficaram componentes que se referem ao que o dinheiro representa no nível da coletividade mais ampla, ou seja: Desigualdade, Progresso e Cultura. Estes resultados permitem concluir que o dinheiro assume dimensão de preocupação eminentemente social em nosso país, contrastando com a tônica das pesquisas conduzidas em outros contextos, que têm focalizado a dimensões de significado do dinheiro relacionadas ao nível individual.

A exploração em separado de cada região permitiu desenhar perfis mais e menos diferenciados do perfil brasileiro geral: Maior diferenciação foi encontrada no Norte e no Nordeste, enquanto Sudeste e Distrito Federal foram mais representativos do perfil nacional, talvez como resultado da maior imigração. Estes resultados contrariaram a idéia de que a hegemonia econômico-cultural das regiões mais desenvolvidas teria o poder de provocar imposição absoluta de padrões de pensamento e comportamento, levando à perda das iden- 
tidades culturais nas áreas menos desenvolvidas. Ficou fortalecida a proposição de uma relação mais complexa, que envolve re-semantização e limitação da absorção do padrão dominante pelas culturas locais (van der Geest, 1997). Colocouse também a questão do peso relativo das variáveis geográficas, culturais e econômicas como determinantes do significado do dinheiro, na medida em que Norte e Nordeste foram não apenas diferentes do padrão Brasil, como também apresentaram perfis diferentes entre si; a região Sul também se diferenciou não apenas em relação ao geral, como também ao Sudeste, de onde está mais próxima e apresenta desenvolvimento econômico mais semelhante.

O exame em separado da região Sudeste colocou em relevo a diversidade interna da região de maior densidade demográfica do país. A composição da amostra permitiu, dentro de certos limites, explorar o efeito do nível de urbanização e tamanho das cidades sobre o significado do dinheiro. Os resultados indicaram a pertinência deste tipo de estudo, sugerindo a necessidade de focalizar variáveis como tamanho das cidades, índices de desenvolvimento econômico, localização regional e proximidade geográfica aos grandes pólos econômicos, ao lado de caracterização histórica e cultural.

\section{Referências}

Brazilian Embassy in London. (1998). The five regions of Brasil. Acesso em 05 de setembro de 1998, de www.brazil.org.uk/page.php?cid=80.

Furnham, A. (1984). Many sides of the coin: The psychology of money usage. Personality \& Individual Differences, 5(5), 501-509.

Furnham, A. (1996). Attitudinal correlates and demographic predictors of monetary beliefs and behaviours. Journal of Organisational Behavior, 17(4), 375-388.

Furnham, A., Kirkcaldy, B. D., \& Lynn, R. (1994). National attitudes to competitiveness, money, and work among young people: First, second, and third world differences. Human Relations, 47(1), 119-132.

Gresham, A., \& Fontenote, G. (1989). The different attitudes of the sexes toward money: An application of the money attitude scale. Advances in Marketing, 8, 380-384.

Instituto Brasileiro de Turismo. (1998). Informações turísticas sobre o Brasil. Acesso em 05 de julho de 1998, de www.embratur.gov.br/.
Lynn, R., Yamauchi, H., \& Tachibana, Y. (1991). Attitudes related to work of adolescents in the United Kingdom and Japan. Psychological Reports, 68(2), 403-410.

Medina, J. F., Saegert, J., \& Gresham, A. (1996). Comparison of MexicanAmerican and Anglo-American attitudes toward money. Journal of Consumer Affairs, 30(1), 124-145.

Moreira, A. S. (2000). Valores e dinheiros: Um estudo transcultural da relação entre prioridades de valores e significado do dinheiro para individuos. Tese de doutorado não-publicada, Universidade de Brasília, Brasília.

Moreira, A. S., \& Tamayo, A. (1999a). Escala de significado do dinheiro: desenvolvimento e validação. Psicologia: Teoria e Pesquisa, 15(2), 93-105.

Moreira, A. S., \& Tamayo, A. (1999b). Escala de significado do dinheiro (ESD): explorando preditores [Resumo]. Sociedade Brasileira de Psicologia (Org.). XXIX Reunião Anual de Psicologia. Campinas: Autor.

Schwartz, S. H. (1994). Are there universal aspects in the structure and contents of human values? Journal of Social Issues, 50(4), 19-45.

Schwartz, S. H. (1999). A theory of cultural values and some implications for work. Apllied Psychology: An International Review, 48(1), 23-47.

Schwartz, S. H., Verkasalo, M., Antonovsky, A., \& Sagiv, L. (1997). Value priorities and social desirability: Much substance, some style. British Journal of Social Psychology, 36(1), 3-18.

Smith, P. B., \& Bond, M. H. (1998). Social psychology across cultures. (2 ed.). London: Prentice Hall Europe.

Smith, P. B., \& Schwartz, S. (1997). Values. In J. W. Berry, M. H. Segall, \& C. Kagitcibasi (Orgs.), Handbook of cross-cultural psychology - social behavior and applications ( $2^{\underline{a}}$ ed., Vol. 3, pp. 77-118). Boston: Allyn and Bacon.

SPSS. (1998). SPSS Base 8.0: User's guide. Chicago: SPSS.

Tabachnick, B. G., \& Fidell, L. S. (1996). Using multivariate statistics. (3 $3^{\underline{a}}$ ed.). New York: Harper Collins College Publishers.

Tang, T. L. P. (1992). The meaning of money revisited. Journal of Organizational Behavior, 13(2), 197-202.

Tang, T. L. P. (2000). A cross-cultural comparison of pay differentials as a function of rater's sex and Money Ethic endorsement: the Matthew Effect revisited. Personality and Individual Differences, 29, 685-697.

van der Geest, S. (1997). Money and respect: the changing value of old age in rural Ghana. Africa, 67(4), 534-559.

Wernimont, P. F., \& Fitzpatrick, S. (1972). The meaning of money. Journal of Applied Psychology, 56, 218-226.

Yamauchi, K. T., \& Templer, D. I. (1982). The development of a money attitude scale. Journal of Personality Assessment, 46(5), 522-528.

Alice da Silva Moreira, Doutora em Psicologia pela Universidade de Brasília, é professora da Universidade Federal do Pará.

Endereço para correspondência: Avenida Serzedelo Corrêa, 1157, Ap. 504. Bairro Batista Campos. 66033770, Belém, PA. Telefone (91)211.2057, Fax: (91)211.1448. E-mail: alicesm@ufpa.br. 